Revista de

Contabilidade e

Organizações

www.rco.usp.br
DOI: http://dx.doi.org/10.11606/rco.v10i26.111420

Journal of

Accounting and

Organizations

\title{
Raciocínio crítico em ambientes virtuais
}

Ivan Carlin Passos ${ }^{\mathrm{a}, \mathrm{c}}$; Edgard Bruno Cornacchione Jr ${ }^{\mathrm{b}}$; Luiz Eduardo Gaio ${ }^{\mathrm{a}, \mathrm{d}}$; Eduardo de Brito ${ }^{\mathrm{a}}$

${ }^{a}$ Centro Universitário Fundação Herminio Ometto de Araras

${ }^{b}$ Universidade de São Paulo

'Universidade Federal Fluminense

${ }^{d}$ Escola de Administração de Empresas de São Paulo

\section{Informações do Artigo}

Histórico do Artigo

Recebido: 25 de fevereiro de 2016

Aceito: 12 de maio de 2016

Palavras-chave:

Raciocínio Crítico,.

Educação Contábil.

Ambiente Virtual de Aprendizagem.

\begin{abstract}
Resumo
Nos últimos anos o Brasil vem ocupando uma posição de destaque econômico no mundo, porém não se observa o mesmo quando se trata de qualidade do ensino, tanto em nível básico quanto superior. As novas gerações nascidas na Era Digital, como a denominada "Geração Y" ou mesmo a "Z" apresentam diversas qualidades, porém dentre suas deficiências, preocupa o fato de adorarem tecnologias que competem com outras atividades que desenvolvem raciocínio critico, como a leitura e solução de problemas. A habilidade de Raciocínio Crítico (Critical Thinking) é enfatizada como importante para diversos tipos de profissionais e pesquisada há muitos anos. O objetivo geral desta pesquisa foi avaliar empiricamente a aplicação do modelo de desenvolvimento de Raciocínio Crítico de Richard Paul no ambiente virtual Moodle em alunos de disciplinas contábeis. Aplicou-se um quase experimento, no primeiro semestre de 2013, em alunos do curso de graduação presencial em Administração na disciplina Orçamento Empresarial e Controladoria de uma Instituição de Ensino Superior do interior do Estado de São Paulo. O instrumento de avaliação de raciocínio crítico foi o Ennis Weir Critical Thinking Essay Test (EWCTET). O principal resultado foi que o modelo de Richard Paul não teve efeito significativo no desenvolvimento de habilidades de raciocínio crítico quando aplicado em uma abordagem mista e via ambiente virtual de aprendizagem Moodle, contrariando pesquisas anteriores. Para futuras pesquisas, sugerem-se amostras maiores que possibilitem melhorar o poder estatístico dos resultados e a investigação de formas de controle que intensifiquem o tempo de dedicação dos alunos nas atividades assíncronas.
\end{abstract}

\section{INTRODUÇÃO}

Copyright $(0) 2016$ FEA-RP/USP. Todos os direitos reservados

A evolução tecnológica na área de ensino vem ocorrem em uma velocidade espantosa. O que antes, os materiais de busca pelo conhecimento ocorriam por meio de uma bibliografia impressa, restrito a poucos, hoje o volume de informação está presente no dia-a-dia da população. Seja por meio de computadores, tablets ou smartphones, todos têm acesso gratuito ao conhecimento desenvolvido e difundido pela humanidade.

As novas gerações nascidas na Era Digital, como a denominada "Geração Y" ou mesmo a "Z" apresentam diversas qualidades, como, por exemplo: são multitarefas, são seletivos em relação às informações, buscam atividades que não somente gerem retorno financeiro, mas os satisfaçam etc. Porém, também se observa que apresentam algumas deficiências, como, por exemplo: não conseguem se atentar a uma aula expositiva por muito tempo, não se aprofundam em leituras, adoram tecnologias que competem com outras atividades que desenvolvem raciocínio critico, como a leitura e solução de problemas etc.

Em 1983, antes mesmo do grande avanço tecnológico e digital, a Comissão Nacional de Excelência em Educação dos Estados Unidos da América elaboraram um relatório denominado "Uma Nação em Risco". Este documento relatava que a maioria dos alunos de dezessete anos de idade não possuía as habilidades intelectuais de que aquele país necessitava. Depois de sua publicação, a maioria dos estados norte americanos desenvolveram programas que encorajavam os professores a ensinarem raciocínio crítico e um dos mais famosos denominado “Táticas para Pensar" vendeu setenta mil exemplares (WILLINGHAM, 2007).

Atualmente os professores concorrem com diversas tecnologias que distraem seus alunos e tiram sua atenção, como: jogos eletrônicos, internet, celulares, redes sociais etc. São diversas as instituições e pesquisadores que procuram desenvolver novas metodologias de ensino e estratégias didáticas que consigam reter a atenção do

Autor Correspondente: Tel (19) 35431400

E-mail: ivanpassos@hotmail.com (I. C. Passos); edgardbc@usp.br (E. B. Cornacchione Jr); gaio@uniararas.br (L. E. Gaio); eduardobrito@uniararas.br (E. Brito) Centro Universitário Herminio Ometto de Araras - Av. Dr. Maximiliano Baruto, 500 - Jd. Universitário - 13607339 - Araras, SP - Brasil 
aluno. Porém, quando se trata de aliar estas estratégias a modelos que melhorem o raciocínio crítico, nota-se no Brasil uma baixa quantidade de pesquisas com este foco.

Dentre os diversos modelos existentes para o desenvolvimento de habilidades e teste de raciocínio crítico, como o CAT (Critical Thinking Assessment Test) desenvolvido por Ennis (1993), California Critical Thinking Skills Test (CCTST) de Facione (1990), Cornell Critical Thinking Test (CCTT) de Ennis et. al. (1985), Critical Thinking Assessment Battery (CTAB) desenvolvido em 1997 e publicado pela American College Testing Program, Watson-Glaser Critical Thinking Appraisal (WGCTA), desenvolvido em 1994 e publicado pela American College Testing Program, entre outros, pode-se citar também o do filósofo norte americano Richard Paul. Ele procura, por meio da identificação dos elementos de um raciocínio, organizar um debate, uma análise de um texto ou mesmo a solução de um problema de forma crítica (PAUL, 1995; PAUL, ELDER, 2000).

Baseado no exposto e em pesquisas anteriores (Passos et al. (2013); Passos (2011); Quitadamo et al. (2008); Abrami et al. (2008); Cornacchione, Duncan e Johnson (2007); Braun (2004); Wilson (2002); Pithers e Soden (2000); Allen et al. (1999); Reed (1998); Bonk e Smith (1998); Baril et al. (1998); Stone e Shelley (1997); Kimmel (1995); Sormunen e Chalupa (1994); Riesenmy et al. (1991); Baldwin e Ingram (1991) e Bangert-Drowns e Bankert, (1990)) este trabalho possui a seguinte questão de pesquisa: Existe relação entre a aplicação do modelo de Richard Paul em ambientes virtuais de aprendizagem e o desenvolvimento de habilidades de raciocínio crítico em alunos de disciplinas contábeis?

Com vistas a atrair a atenção do aluno com uma ferramenta tecnológica, o objetivo geral do trabalho foi avaliar empiricamente a efetividade em ensinar o modelo de Richard Paul, via ambiente virtual de aprendizagem (Moodle), em alunos do ensino superior, especificamente, em alunos de uma disciplina contábil. A escolha de uma disciplina da área contábil foi devido à formação do pesquisador e à intenção de comparação com o trabalho de Passos (2011), que em sua tese obteve resultados positivos no desenvolvimento de raciocínio crítico em alunos da área. O autor citado justificou a escolha explicando que a internacionalização e harmonização das Normas Contábeis Brasileiras, após a aprovação da lei 11.638/07 (Nova Lei das Sociedades Anônimas), aumentou a demanda por profissionais contábeis com maiores níveis de raciocínio crítico.

Sendo assim, os objetivos específicos deste trabalho foram:

- Analisar a distribuição do EWCTET por método de instrução;

- Avaliar as habilidades de raciocínio crítico de ambas as classes (experimento e controle);

O trabalho se justifica pela sua contribuição em dar continuidade às pesquisas sobre o tema, principalmente, testando as hipóteses dos estudos anteriores no Brasil, de forma a verificar se o alunado nacional possui as mesmas características dos internacionais pesquisados. $\mathrm{O}$ estudo também contribui para aumentar a quantidade de investigações desta natureza no Brasil, além de relacionar o assunto com outras tecnologias da educação, em especial, os ambientes virtuais de aprendizagem, uma vez que a literatura ainda é carente de análise destes testes nas mais modernas tecnologias educacionais.

$\mathrm{O}$ artigo teve início com a introdução do assunto e algumas definições metodológicas da pesquisa desenvolvida. A segunda parte versa sobre a revisão bibliográfica, a terceira seus procedimentos metodológicos, a quarta apresenta a análise dos dados e a quinta uma discussão sobre as principais conclusões, abordando suas limitações e sugestões para futuras pesquisas.

\section{REVISÃO DA LITERATURA}

Nos Estados Unidos da América a literatura que trata do tema Critical Thinking, termo neste trabalho traduzido como Raciocínio Crítico, é vasta e o assunto é estudado há décadas. Não há consenso no Brasil sobre a tradução do termo, encontrando-se muitas palavras para seu significado, como, por exemplo: Pensamento Crítico, Pensando Criticamente, Argumentação Lógica, Raciocínio Lógico etc.

As definições muito se assemelham, porém também não são consensuais, como se pode analisar na Tabela 1 abaixo: 
Tabela 1. Definições de Raciocínio Crítico

Autor

MCPECK (1981)

LIPMAN (1988)

SIEGEL (1988)

FACIONE et al (1990)

ENNIS (1993)

PAUL (1995)

PASSOS (2011)
Definição
[...] o principal significado do raciocínio crítico é a propensão e habilidade de se engajar em uma atividade com ceticismo reflexivo.

[...] pensamento que facilita julgamento porque ele se baseia em critérios, autocorreção e é sensitivo ao contexto.

[...] o foco nas razões e no poder das razões para assegurar ou justificar crenças, alegações e ações. Um pensador crítico, então, é alguém que é apropriadamente movido pelas razões: ele tem a propensão ou atitude de acreditar e agir de acordo com razões; e ele tem a habilidade apropriada para avaliar a força das razões em muitos contextos nos quais elas desempenham uma função.

Nós entendemos raciocínio crítico como julgamento objetivo e auto regulatório que resulta em interpretação, análise, avaliação e inferência, e também como uma explicação das considerações evidenciais, conceituais, metodológicas, criteriológicas ou contextuais sobre o que o julgamento está baseado.

[...] pensamento reflexivo racional que é focado em decidir em que acreditar ou fazer.

Se o pensamento é disciplinado para servir os interesses de um indivíduo ou grupo para a exclusão de outras pessoas ou grupos, nós chamamos de raciocínio crítico sofistico ou fraco senso. Se o pensamento é disciplinado para levar em conta os interesses de diversas pessoas ou grupos, nós podemos chamar de raciocínio crítico justo ou forte senso.

Raciocínio crítico é pensamento que facilita julgamento, pois identifica, analisa e julga os elementos de um raciocínio. Os elementos de um raciocínio são: objetivo, problema, informações, interpretações, conceitos, suposições, implicações e ponto de vista.

Fonte: Elaboração própria

Analisando a tabela, constata-se que existe consenso em relação ao raciocínio crítico ser um pensamento organizado, envolver julgamento e analisar as argumentações e fatos apresentados sobre um objeto discutido. $\mathrm{O}$ bom pensador crítico estará disposto a mudar sua opinião baseado na análise de novos julgamentos, argumentos ou fatos apresentados que melhor elucidem o objeto discutido, seja ele uma conversa, um debate, a análise de um artigo, livro ou mesmo um filme.

Em 2008, uma meta-análise identificou e resumiu as evidências empíricas disponíveis em 117 estudos abrangendo 20.698 participantes sobre o impacto de intervenções no desenvolvimento das habilidades ou atitudes de raciocínio crítico dos alunos. Esse trabalho concluiu que o tipo de intervenção e metodologia de ensino está relacionado com os níveis de desenvolvimento de raciocínio crítico. Com esta pesquisa, tornou-se evidente que o aprimoramento ou desenvolvimento das habilidades ou atitudes de raciocínio crítico dos alunos não podem ser uma mera expectativa implícita dos projetos pedagógicos e educadores (ABRAMI et al, 2008).

Em 2007, um artigo publicado na área contábil no Brasil explorou, em uma amostra de 65 estudantes de graduação e pós-graduação em Ciências Contábeis da Faculdade de Economia, Administração e Contabilidade da Universidade de São Paulo (FEA-USP), as habilidades de raciocínio crítico, leitura e escrita. Por meio de análises estatísticas, o estudo focou os elementos para a melhoria do desempenho dos estudantes em relação as suas habilidades de raciocínio crítico. Este trabalho refletiu sobre o papel dos educadores como agentes de mudanças no cenário da educação superior. Os resultados apontaram para indicações de boa qualidade de escrita e evidência de níveis elevados de raciocínio crítico. Não foram observadas diferenças significativas nas métricas 
sobre níveis de facilidade de leitura dos produtos escritos gerados. O estudo sugeriu ainda que diferenças culturais sobre raciocínio crítico, relacionadas com a percepção de autoridade, sejam examinadas em futuras investigações. (CORNACCHIONE; DUNCAN; JOHNSON, 2007).

Em 1998, Jennifer H. Reed defendeu sua tese que investigou a aplicação do modelo de Richard Paul para desenvolvimento de raciocínio crítico em um curso de História Norte Americana. O objetivo da intervenção foi desenvolver: habilidades para pensar criticamente sobre História Norte Americana e sobre assuntos diários; atitudes para pensar criticamente; e conhecimento sobre o conteúdo de História Norte Americana. A pesquisa examinou também se a idade ou gênero influenciava a eficiência do método de instrução (REED, 1998).

Passos (2011) e Passos et al. (2013) continuaram o trabalho de Reed (1998) e aplicaram o modelo de desenvolvimento de raciocínio crítico de Richard Paul em alunos de disciplinas contábeis. Primeiramente, um quase-experimento piloto foi realizado em uma instituição pública durante o segundo semestre de 2010, ele foi aplicado em uma abordagem geral (quatro intervenções de $30 \mathrm{~min}$.) e o autor da pesquisa foi monitor das classes. No primeiro semestre de 2011, o segundo quase experimento foi realizado em uma instituição particular, teve uma abordagem mista (aulas e atividades da turma experimento) de aplicação e o autor da pesquisa foi o professor das turmas. Nos dois quase experimentos os participantes preencheram três instrumentos de avaliação: dois deles aplicados no início e no final do semestre e avaliaram habilidades (Ennis Weir Critical Thinking Essay Test EWCTET) e atitudes (California Critical Thinking Dispositions Inventory - CCTDI) de raciocínio crítico; e um deles foi uma pesquisa demográfica (aplicado no final do semestre). Foram realizadas análises descritivas das amostras e para testar as hipóteses foi aplicada a análise de covariância (ANCOVA) utilizando-se os pré-testes como covariáveis. Na instituição pública não foi constatado efeito significativo do modelo no desenvolvimento de habilidades ou atitudes de raciocínio crítico e nenhuma diferença considerando o efeito isolado das variáveis idade ou gênero. $\mathrm{Na}$ instituição particular foram confirmadas duas hipóteses: a turma experimento $(\mathrm{p}=0,040$ e $\mathrm{d}=0,56)$ e os alunos mais velhos $(\mathrm{p}=0,047$ e $\mathrm{d}=0,58)$ apresentaram maior desenvolvimento de habilidades de raciocínio crítico. Apesar de as médias das atitudes não terem sido significativamente diferentes, encontrou-se também efeito significativo do modelo instrucional no desenvolvimento da atitude curiosidade $(p=0,047$ e $d=0,65)$. Também foram constatadas diferenças significativas nas habilidades para os efeitos isolados de idade $(p=0,002 \mathrm{e} d=0,77)$ e gênero $(p=0,016$ e $d=0,60)$; e para as atitudes no efeito isolado do gênero $(p=0,033$ e $d=0,46)$.

O modelo de Richard Paul considera elementos de raciocínio e padrões intelectuais universais que são utilizados para desenvolver o raciocínio e as atitudes críticas das pessoas. Paul apresenta sua abordagem para desenvolvimento de raciocínio crítico como um modelo geral que pode ser aplicado a qualquer problema ou assunto que requer raciocínio, sua teoria é a de que para desenvolver raciocínio crítico nos alunos é preciso ensinálos a pensar criticamente (REED, 1998). Espera-se que os resultados da aplicação deste modelo por meio de um ambiente virtual de aprendizagem tragam contribuições às pesquisas sobre educação na área de negócios e ajude os professores a pensarem em utilizar novas metodologias que possam desenvolver habilidades e atitudes requeridas pelo mercado de trabalho.

\section{ASPECTOS METODOLÓGICOS}

O trabalho aplicou um protocolo de pesquisa semelhante aos de Reed (1998), Passos (2011) e Passos et al. (2013) com pré-testes e pós-testes avaliando habilidades de raciocínio crítico. Primeiramente foi realizada as análises descritivas e correlações dos dados demográficos e acadêmicos dos alunos. O intuito foi verificar possíveis variáveis que poderiam explicar as diferenças dos desempenhos entre as classes. Como não foi possível sortear cada aluno para o grupo experimento e sim a classe como um todo, a pesquisa foi classificada como um quase experimento (BICKMAN; ROG, 1998).

Escolheu-se a abordagem Mista de aplicação do modelo de desenvolvimento de raciocínio crítico de Richard Paul. Ennis (1993) classifica as abordagens para ensinar raciocínio crítico:

- Geral: independentemente do conteúdo, as habilidades de raciocínio crítico são ensinadas aos alunos.

- Infusão: requer profunda reflexão sobre um assunto e, adicionalmente, princípios gerais de raciocínio crítico são ensinados e aplicados nas atividades desenvolvidas.

- Imersão: os alunos são incentivados a pensar criticamente sobre determinado assunto; porém, os princípios gerais de raciocínio crítico não são apresentados. 
- $\quad$ Misto: uma mistura do Geral com Infusão ou Imersão, os alunos estão envolvidos em um curso em que analisam criticamente um assunto com ou sem os conceitos gerais de raciocínio crítico explícitos; porém, há uma parte separada do curso que tem como objetivo ensinar princípios gerais de raciocínio crítico.

O modelo de Richard Paul para desenvolvimento de raciocínio crítico foi ensinado via Moodle e aplicado para a classe experimento, a outra classe do mesmo semestre e disciplina recebeu um método tradicional de ensino. As intervenções assíncronas na turma experimento foram semanais e em noventa por cento dos casos via ambiente virtual de aprendizagem, pois na maioria das vezes um breve fechamento da atividade era realizado presencialmente e sempre um incentivo para a média final era utilizado. Utilizaram-se textos jornalísticos, artigos científicos, capítulos de livros e situações problema para debates utilizando o modelo de raciocínio crítico de Richard Paul. Para cada atividade havia um texto orientador que explicava como utilizar o modelo de Paul, as dúvidas podiam ser expostas em Fóruns específicos. Optou-se por atividades assíncronas, por se tratar de atividades extraclasse, não tornando possível a obrigatoriedade de participação em um a atividade agendada. Foram aplicados pré-testes ao início da terceira semana de aula e pós-testes ao final do semestre para avaliar as habilidades de raciocínio crítico dos alunos (EWCTET).

O Ennis-Weir Critical Thinking Essay Test (EWCTET) foi aplicado para avaliar a habilidade dos estudantes em analisar um argumento e responder criticamente por escrito um assunto em questão. Este instrumento avalia a habilidade de responder a argumentos quando eles aparecem naturalmente em uma discussão, disputa ou debate do mundo real (ENNIS; WEIR, 1985; CORNACCHIONE, DUNCAN; JOHNSON, 2007; REED, 1998; PASSOS, 2011; PASSOS et al., 2013). O teste possui uma página escrita pelo editor de um jornal que procura convencer o público sobre a adoção de uma lei que proíba estacionar em ruas públicas à noite. A carta possui oito parágrafos numerados e outro com um sumário. Os participantes precisam analisar cada parágrafo da carta teste com o objetivo de escrever uma curta redação concordando ou discordando de cada argumento exposto. Os responsáveis por desenvolver o teste criaram um formulário com os critérios para avaliar cada um dos nove parágrafos escritos em resposta à carta. Os alunos podem atingir notas de -9 a 29. Nas análises dos primeiros oito parágrafos pode-se atingir de -1 (analisou incorretamente) até 3 (analisou e justificou corretamente). No último parágrafo os critérios de correção permitem avaliá-lo de -1 até 5 . O tempo máximo de duração recomendado é de 40 minutos. Para mais informação sobre o método consulte Ennis e Weir (1985).

O Prof. Robert H. Ennis é um especialista no assunto e possui diversos artigos publicados na área. Reed (1998) comenta que o EWCTET tem sido utilizado em muitas pesquisas e tem recebido forte apoio de especialistas. Cornacchione, Duncan e Johnson (2007), Passos (2011), Passos et al. (2013) e a presente pesquisa obtiveram autorização dos Professores Ennis e Weir para a utilização do teste. A confiabilidade do teste é analisada utilizando-se dois diferentes avaliadores para 27 redações escritas por estudantes de um curso de lógica informal e 28 redações de alunos do oitavo ano do curso de inglês. Obtiveram-se correlações de 0,86 e 0,82, respectivamente, as quais são altas para um teste redacional. A literatura sobre testes aborda quatro tipos de validade: conteúdo, preditiva, concordância e construção. A validade mais apropriada para o EWCTET é a de conteúdo (ENNIS; WEIR, 1985).

Os testes são aplicados para ambas as turmas. Cada turma com o professor específico. As notas do EWCTET foram as médias de dois avaliadores. No processo de avaliação qualquer diferença maior do que três pontos faz com que a redação seja revisada e discutida pelos avaliadores, até atingir à diferença máxima de três pontos. As revisões de ambas as turmas (controle e experimento) são realizadas em uma única sessão (REED, 1998; PASSOS, 2011; PASSOS et al., 2013). Logo após a primeira correção (antes das revisões) dos avaliadores é calculada e analisada a confiabilidade do teste por meio do coeficiente de correlação ( $\mathrm{r}$ de Pearson).

A análise estatística busca testar diferenças significativas entre as duas classes. Como as turmas apresentam os escores com diferença significativa de uma distribuição normal, opta-se por utilizar três testes não paramétricos: o teste de Mann-Whitney; o teste da soma dos postos de Wilcoxon e o teste dos postos com sinais de Wilcoxon (FIELD, 2009). Para validar o modelo de pesquisa em relação à possível viés na qualidade da metodologia de ensino por parte dos instrutores, é solicitado acesso às avaliações do corpo docente da instituição referente às turmas e não se nota diferenças significativas entre as avaliações dos dois professores. Todos os participantes sabem que estavam fazendo parte de uma pesquisa e para evitar o efeito Hawthorne, eles não sabem se pertencem ao grupo controle ou experimento.

Portanto, resumidamente, a metodologia da pesquisa empírica segue as seguintes etapas:

1. Aplicação do modelo de Richard Paul via ambiente Moodle em uma classe do curso de graduação presencial em Administração na disciplina Orçamento Empresarial e Controladoria de uma Instituição de Ensino Superior (IES) do interior do Estado de São Paulo; 
2. Aplicação de um método tradicional de ensino em uma classe do mesmo semestre e disciplina citada acima, na mesma instituição;

3. Aplicação de um pré-teste e um pós-teste do EWCTET que avalia habilidades de raciocínio crítico de ambas as classes (experimento e controle); e

4. Comparação dos resultados com pesquisas anteriores, em especial as pesquisas de Reed (1998), Passos (2011) e Passos et al. (2013).

Utilizaram-se os softwares SPSS for Windows versão 13.0 e o Excel 2010 para a execução dos tratamentos estatísticos e análise dos dados.

\section{RESULTADOS E DISCUSSÃO}

Primeiramente analisaram-se alguns dados demográficos que serviram de apoio para as possíveis explicações dos resultados e comparações com pesquisas anteriores.

Do total de 18 alunos da turma experimento do curso de Administração matutino, 13 alunos optaram por participar da pesquisa e preencheram os pré-testes no início do semestre e os pós-testes ao final. Possuíam uma faixa etária média de 21,8 anos; a maioria (69\%) do gênero masculino; o ano de formatura no ensino médio mais frequente foi o de 2009; apenas um aluno era casado; apenas um aluno possuía um filho; a renda familiar média era de 5,7 salários mínimos; a maioria (54\%) disse que "raramente" liam algum livro ou artigo, enquanto os outros (46\%) afirmaram ler "frequentemente"; e a maioria (77\%) não falava fluentemente uma língua estrangeira, enquanto uma minoria $(23 \%)$ disse falar a língua Inglesa.

$\mathrm{Na}$ turma controle do curso de Administração noturno de um total de 43 alunos, 15 alunos optaram em participar da pesquisa e preencheram os dois testes. A faixa etária média era de 22,0 anos, a maioria (67\%) era do sexo feminino; a moda para o ano de formatura foi 2010; todos os alunos eram solteiros; nenhum possuía filhos; a média da renda familiar era de 7,0 salários mínimos; houve mais respostas (53\%) "frequentemente” em relação ao hábito de leitura, seguido de "raramente" (40\%) e por último "quase nunca" (7\%); e a maioria (67\%) negou falar alguma língua estrangeira, enquanto alguns (33\%) afirmaram falar fluentemente a língua Inglesa. Apesar de se tratar de turmas em turnos diferentes (matutino e noturno) do curso de Administração o perfil do aluno não se altera significativamente. Observado pelo questionário sócio econômico disponível na IES.

Analisando os dados das duas turmas se verifica que exceto pelo percentual de cada turma que optou em participar da pesquisa preenchendo todos seus requisitos e pelo gênero, as demais variáveis: faixa etária, ano de formatura no ensino médio, estado civil, quantidade de filhos, renda familiar, hábito de leitura e língua estrangeira eram bem parecidas o que possibilita o quase experimento. As duas exceções são consideradas nas análises dos resultados e compõem a lista de possíveis limitações do presente estudo.

A Tabela 2 a seguir apresenta estatísticas descritivas do EWCTET das turmas experimento e controle em seus pré-testes e pós-testes.

Tabela 2. Distribuição do EWCTET por método de instrução

\begin{tabular}{lcccc}
\hline & \multicolumn{2}{c}{ Turma Experimento $(\mathrm{n}=13)$} & \multicolumn{2}{c}{ Turma Controle $(\mathrm{n}=15)$} \\
\hline Medidas & Pré-teste & Pós-teste & Pré-teste & Pós-teste \\
Média & 4,92 & 6,38 & 3,13 & 4,60 \\
Mediana & 5,00 & 4,00 & 2,00 & 5,00 \\
DP & 10,04 & 8,37 & 9,06 & 2,08 \\
\hline
\end{tabular}

Fonte: SPSS versão 13.0

Nota-se que ambas as turmas obtiveram resultados médios maiores nos pós-testes, porém é necessário testar se há diferença significativa entre os pós-testes e pré-testes dentro e entre cada turma para inferir sobre possíveis relações entre o método de instrução no ambiente virtual Moodle e o desenvolvimento de habilidades de raciocínio crítico. 
Analisaram-se os histogramas e uma das distribuições aparentou não ser normal. O teste KolmogorovSmirnov (K-S) confirmou que os escores do pré-teste da turma controle foram significativos $(\mathrm{p}<0,05)$, indicando que a amostra não era normal. Procurou-se transformar os dados, porém nenhuma das opções (elevar ao quadrado, o logaritmo, a raiz quadrada, elevar ao cubo etc.) foi capaz de corrigir o problema e normalizar a distribuição. Portanto, quando não é possível atender os requisitos de uma ferramenta estatística paramétrica, têm-se como opção os testes não paramétricos (FIELD, 2009).

Para testar diferenças entre duas condições e diferentes participantes de uma distribuição não normal pode-se utilizar o teste não paramétrico de Mann-Whitney e o teste da soma dos postos de Wilcoxon. Pode-se dizer que estes testes são as versões não paramétricas equivalentes ao teste paramétrico t (Student) (FIELD, 2009).

Tabela 3. Posição Média e Soma dos Postos de Mann-Whitney

\begin{tabular}{lllrr}
\hline \multirow{2}{*}{ EWCTETpre } & \multicolumn{1}{c}{ Turma } & N & Posto Médio & Soma dos Postos \\
& Experimento & 13 & 14,88 & 193,50 \\
& Controle & 15 & 14,17 & 212,50 \\
& Total & 28 & & 192,00 \\
EWCTETpos & Experimento & 13 & 14,77 & 214,00 \\
& Controle & 15 & 14,27 & \\
\hline
\end{tabular}

Fonte: SPSS versão 13.0

Analisando a Tabela 3, verifica-se que tanto nos pré-testes quanto nos pós-testes a turma com menor média em seus postos é a controle, logo, pode-se dizer que ela possui o maior número de postos baixos. Este primeiro resultado apresenta indícios positivos do quase experimento, já que a turma experimento obteve postos maiores no teste que mede habilidades de raciocínio crítico. Porém, deve-se analisar com cautela, pois não se pode afirmar que houve melhoria dos pré-testes para os pós-testes dentro de cada turma e nem que os pré-testes e póstestes das turmas são diferentes.

Tabela 4. Teste de Mann-Whitney e Wilcoxon

\begin{tabular}{lcc}
\hline & EWCTETpre & EWCTETpos \\
\hline Mann-Whitney U & 92,500 & 94,000 \\
Wilcoxon W & 212,500 & 214,000 \\
Z & $-0,231$ & $-0,162$ \\
Sig. Assint. (bilateral) & 0,817 & 0,872 \\
Sig. Exata & 0,821 & 0,892 \\
Sig.Exata (bilateral) & 0,829 & 0,883 \\
Sig. Exata (unilateral) & 0,414 & 0,441 \\
Probabilidade Pontual & 0,009 & 0,009 \\
\hline
\end{tabular}

Fonte: SPSS versão 13.0

Verifica-se que os pré-testes da turma controle (Mediana $=2,00)$ parecem não diferir dos da turma experimento (Mediana $=5,00), U=92,50$, não significativo, $5=0,04$. O mesmo acontece em relação aos póstestes, a turma controle (Mediana $=5,00)$ não foi significativamente diferente da turma experimento $($ Mediana $=$ $4,00), \mathrm{U}=94,00$, ns, $5=0,03$. Calculando os tamanhos de efeito, observa-se que $(0,04$ e 0,03$)$ são pequenos, o que indica que seria necessário aumentar o número de participantes para alcançar maiores poderes estatísticos.

O resultado do teste acima indica que não há diferenças estaticamente significativas entre os pré-testes e entre os pós-testes das turmas controle e experimento, dando indícios que o modelo de Richard Paul aplicado via Moodle ao longo do semestre não desenvolveu habilidades de raciocínio crítico nos alunos da turma experimento.

O teste dos postos com sinais de Wilcoxon é um teste não paramétrico semelhante ao teste $\mathrm{t}$ dependente que pode ser utilizado em situações em que existem dois conjuntos de escores dos mesmos participantes (FIELD, 2009). Portanto, nesta pesquisa será utilizado para testar se houve em cada turma mudança nas habilidades de 
raciocínio crítico ao longo do semestre.

Tabela 5. Sinais dos Postos de Wilcoxon para Turma Controle

\begin{tabular}{lllcc}
\hline & & N & Postos Médios & Soma dos Postos \\
\hline EWCTETpos - EWCTETpre & Postos Negativos & $5^{\text {a }}$ & 6,30 & 31,50 \\
& Postos Positivos & $8^{\mathrm{b}}$ & 7,44 & 59,50 \\
& Iguais & $2^{\mathrm{c}}$ & & \\
& Total & 15 & & \\
\hline
\end{tabular}

Fonte: SPSS versão 13.0

Nota: a) EWCTETpos < EWCTETpre, b) EWCTETpos $>$ EWCTETpre e c) EWCTETpos = EWCTETpre

De acordo com a Tabela 5, verifica-se que a maioria (8) dos alunos da turma controle obteve melhor desempenho nos pós-testes em relação aos pré-testes. Em um primeiro momento este resultado parece indicar que houve melhoria nas habilidades de raciocínio crítico da turma controle.

Tabela 6. Teste dos Postos com Sinais de Wilcoxon para Turma Controle

\begin{tabular}{lc}
\hline & EWCTETpos - EWCTETpre \\
\hline$Z$ & $-0,980^{\mathrm{a}}$ \\
Sig. Assint. (bilateral) & 0,327 \\
Sig.Exata (bilateral) & 0,347 \\
Sig. Exata (unilateral) & 0,174 \\
Probabilidade Pontual & 0,009 \\
\hline
\end{tabular}

Fonte: SPSS versão 13.0

Nota: a) Baseado nos Postos Negativos

Analisando as Tabelas 5 e 6, pode-se dizer que os pós-testes (Mediana $=5,00$ ) não foram significativamente mais altos que os pré-testes (Mediana $=2,00)$ da turma controle, $\mathrm{T}=6,30, \mathrm{~ns}, 5=0,19$, portanto, não se pode afirmar que houve aumento nas habilidades de raciocínio crítico nesta turma ao longo do semestre. O tamanho de efeito $(0,19)$ é de pequeno a médio, logo, sugere-se que futuras pesquisas procurem aumentar o número de participantes para obter maiores poderes estatísticos.

Tabela 7. Sinais dos Postos de Wilcoxon para Turma Experimento

\begin{tabular}{lllcc}
\hline & & N & Postos Médios & Soma dos Postos \\
\hline EWCTETpos - EWCTETpre & Postos Negativos & $4^{\mathrm{a}}$ & 6,88 & 27,50 \\
& Postos Positivos & $8^{\mathrm{b}}$ & 6,31 & 50,50 \\
& Iguais & $1^{\mathrm{c}}$ & & \\
& Total & 13 & & \\
& & &
\end{tabular}

Fonte: SPSS versão 13.0

Nota: a) EWCTETpos < EWCTETpre, b) EWCTETpos $>$ EWCTETpre e c) EWCTETpos $=$ EWCTETpre

Analisando a Tabela 7 acima, pode-se observar que a maioria (8) dos alunos teve melhor desempenho nos pós-testes em relação aos pré-testes. Porém, não se pode afirmar que isto se deve exclusivamente ao modelo de desenvolvimento de raciocínio crítico de Richard Paul, já que este teste estatístico não mede esta interação. Caso 
as amostras tivessem se apresentado como normais, a ANCOVA conseguiria testar esta interação, pois trabalha com um modelo de regressão múltipla em que uma das variáveis independentes é a turma, ou seja, o quanto que a intervenção explica do modelo de uma turma em relação à outra poderia ser testado.

Tabela 8. Teste dos Postos com Sinais de Wilcoxon para Turma Experimento

\begin{tabular}{lc}
\hline & EWCTETpos - EWCTETpre \\
\hline$Z$ & $-0,904^{\mathrm{a}}$ \\
Sig. Assint. (bilateral) & 0,366 \\
Sig.Exata (bilateral) & 0,395 \\
Sig. Exata (unilateral) & 0,197 \\
Probabilidade Pontual & 0,015 \\
\hline
\end{tabular}

Fonte: SPSS versão 13.0

Nota: a) Baseado nos Postos Negativos

De acordo com as Tabelas 7 e 8, verifica-se que para os alunos da turma experimento os pós-testes $($ Mediana $=4,00)$ não foram significativamente mais altos que os pré-testes (Mediana $=5,00), \mathrm{T}=6,88, \mathrm{~ns}, 5$ $=0,18$. Observa-se que o tamanho de efeito $(0,18)$ é de pequeno a médio, indicando que um maior número de participantes melhoraria o poder estatístico. Portanto, pode-se dizer que não houve diferença significativa entre os pós-testes e os pré-testes da turma experimento, apesar de a maioria dos alunos terem melhorado sua posição nos pós-testes. As análises indicam que não houve desenvolvimento de raciocínio crítico utilizando o modelo de Richard Paul em uma abordagem mista no ambiente virtual Moodle. Porém, a pesquisa propicia o aumento da discussão sobre diferentes metodologias e recursos que possam ao mesmo tempo melhorar o aprendizado do aluno e desenvolver habilidades requeridas pelo mercado profissional e acadêmico.

Comparando estes resultados com pesquisas anteriores, verifica-se que este estudo foi contra o de Reed (1998), a qual constatou em sua tese que os alunos de graduação do curso de História que foram expostos ao modelo de raciocínio crítico de Richard Paul obtiveram melhor resultado no EWCTET (REED, 1998). A autora também utilizou uma abordagem mista, na qual as intervenções foram frequentes, porém todas foram presenciais e não houve suporte de um ambiente virtual de aprendizagem.

Em relação às pesquisas de Passos (2011) e Passos et al. (2013) que realizaram dois quase-experimentos, um em uma abordagem geral e outro em um mista, este estudo corrobora os resultados do primeiro diferindo em relação à abordagem (geral versus mista) e contraria o segundo que possuiu a mesma abordagem (mista). Porém, comparando o da abordagem semelhante, entende-se que uma das possíveis explicações pode ser a intensidade das intervenções no modelo presencial, já que uma das limitações no modelo virtual foi o não acompanhamento do tempo dispendido pelos alunos na solução e análise das atividades assíncronas.

Ao se comparar as médias obtidas nos pós-testes das turmas experimento $(6,38)$ e controle $(4,60)$ com dados de pesquisas anteriores do Suplemento do Manual do EWCTET (Universidade A = 13,1 e Universidade B $=14,3$ ) (ENNIS, 1998), com o resultado da pesquisa de Cornacchione, Duncan e Johnson (2007) (Grupo USP $=15,1)$ e com os trabalhos de Passos (2011) e Passos et al. (2013) (FEA-USP = 12,50; Instituição particular = 4,91), pode-se dizer que o desempenho dos alunos desta pesquisa foi bem abaixo das instituições internacionais e públicas brasileiras citadas, porém bem parecido com o da instituição particular do estudo de Passos (2011), sugerindo futuras pesquisas que analisem o raciocínio crítico por tipo de instituição (por exemplo: privada versus pública).

Além do estudo de Reed (1998) e Passos (2011), o resultado desta pesquisa foi contra as teorias ou conclusões das seguintes pesquisas: Abrami et al. (2008); Quitadamo et al. (2008); Cornacchione, Duncan e Johnson (2007); Braun (2004); Wilson (2002); Pithers e Soden (2000); Allen et al. (1999); Bonk e Smith (1998); Baril et al. (1998); Stone e Shelley (1997); Kimmel (1995); Sormunen e Chalupa (1994); Riesenmy et al. (1991); Baldwin e Ingram (1991) e Bangert-Drowns e Bankert, (1990). No entanto, corroborou os resultados dos seguintes estudos: McMillan (1987); Adams (1999) e Passos et al. (2013). A maioria dos estudos citados foram realizados com alunos de graduação, utilizaram abordagens e modelos variados e não utilizaram ambientes virtuais, mas possuem uma similaridade na intenção de desenvolver habilidades de raciocínio crítico. 


\section{CONCLUSÕES}

O principal resultado desta pesquisa respondeu seu problema: os alunos da turma experimento não se saíram melhor do que os alunos da turma controle em um teste que avalia habilidades de raciocínio crítico. Logo, pode-se dizer que o modelo de Richard Paul não teve efeito significativo no desenvolvimento de habilidades de raciocínio crítico quando aplicado em uma abordagem mista e via ambiente virtual de aprendizagem Moodle.

Refletindo sobre as ideias de Lipman (2003), pensar significa a possessão de um conceito, uma opinião ou uma crença, e isso não implica o uso de bom julgamento. Qualquer pensamento que envolve critério, comparação e se baseie em padrões é raciocinar. O modelo de raciocínio crítico aplicado na turma experimento via Moodle pretendeu incentivar os alunos a utilizarem critérios e padrões para pensar sobre determinado objeto de estudo (artigo, livro, problema etc.).

A aplicação do modelo de desenvolvimento de habilidades de raciocínio crítico de Richard Paul em uma abordagem mista, explicando como utilizar o modelo e aplicando em diversas atividades durante um semestre já obteve resultado positivo em pesquisas anteriores (PASSOS, 2011; REED, 1998; ABRAMI et al, 2008), porém via um ambiente virtual de aprendizagem não se encontrou uma prévia investigação. Uma das possíveis explicações para o resultado negativo pode ser atribuída à baixa intensidade das aplicações, fato que não foi observado via ambiente virtual de aprendizagem nas atividades assíncronas e que desperta interesse para possíveis maneiras de seu controle em futuros trabalhos.

Analisando os dados das duas turmas em busca de prévias diferenças das habilidades de raciocínio crítico, verifica-se que o percentual de cada turma que optou em participar da pesquisa e a variável gênero compõe a lista de possíveis limitações do presente estudo. Esta investigação se justifica por dar continuidade ao tema, às pesquisas anteriores e pela inserção da variável ambiente virtual de aprendizagem como um atrativo aos alunos das novas gerações. Esta pesquisa contribui para o aumento da discussão sobre diferentes metodologias, ferramentas e recursos que possam ao mesmo tempo melhorar o aprendizado do aluno e desenvolver habilidades requeridas pelo mercado profissional e acadêmico.

Para futuras pesquisas se sugere amostras maiores, tornando possível melhorar o poder estatístico dos resultados e a investigação de formas de controle que intensifiquem o tempo de dedicação dos alunos nas atividades síncronas ou assíncronas (via ambiente virtual de aprendizagem). Devido aos resultados dos testes de alunos de instituições particulares terem ficado bem abaixo das universidades internacionais e brasileiras públicas, sugere-se que futuras investigações considerem a variável tipo de instituição (pública versus particular). Sugere-se também, que futuras pesquisas apliquem o modelo em cursos de graduação ou pós-graduação em diferentes abordagens (Geral, Infusão, Imersão ou Mista) e com diferentes ambientes virtuais de aprendizagem, ferramentas e recursos tecnológicos, como por exemplo: jogos de empresas, tablets, celulares, fóruns de discussão, quizzes etc. (ENNIS, 1993).

\section{REFERÊNCIAS}

ABRAMI, Phillip C. ; BERNARD, Robert M. ; BOROKHOVSKI, Evgueni; WADE , Anne; SURKES , Michaela; TAMIM, Rana and ZHANG, Dai. Instructional Interventions Affecting Critical Thinking Skills and Dispositions: A Stage 1 Meta-Analysis. Review of Educational Research, December 2008, Vol. 78, № 4, pp. $1102-1134$.

ADAMS, Barbara L. Nursing education for critical thinking: An integrative review. Journal of Nursing Education. [S.1.], v. 38, p. 111-119, 1999.

ALLEN, Mike et al. A meta-analysis of the impact of forensics and communication education on critical thinking. Communication Education. [S.1.], v. 48, issue 1, 1999.

BALDWIN, B.; INGRAM, R. Rethinking the objectives and content of elementary accounting. Journal of Accounting Education. [S.1.], v. 9, p. 1-14, 1991.

BANGERT-DROWNS, R. L.; BANKERT. E. Meta-analysis of effects of explicit instruction for critical thinking. In: ENCONTRO ANUAL DA ASSOCIAÇÃO DE PESQUISA EDUCACIONAL AMERICANA, 1990, Boston. Anais... Boston, 1990. Disponível em: <http://eric.ed.gov> ( ${ }^{\circ}$ ED 328614). Acesso em: 25/06/2010. 
BARIL, Charles P.; CUNNINGHAM, Billie M.; FORDHAM, David R.; GARDNER, Robert L.; WOLCOTT, Susan K. Critical Thinking in the Public Accounting Profession: Aptitudes and Attitudes. Journal of Accounting Education, Vol. 16, N 3/4, pp. 381-406, 1998.

BICKMAN, Leonard; ROG, Debra J. Handbook of applied social research methods. CA, USA: SAGE, 1998.

BONK, Jay Curtis; SMITH, G. Stevenson. Alternative Instructional Strategies for Creative and Critical Thinking in the Accounting Curriculum. Journal of Accounting Education, Vol. 16, n², pp. 261-293, 1998.

BRAUN, N. M. Critical thinking in the business curriculum. Journal of Education for Business. [S.1.], v. 79, p. 232-236, 2004.

CORNACCHIONE JR., Edgard B.; DUNCAN, John; JOHNSON, Scott D. Critical Thinking Skills of Accounting Students: Habilidade de Raciocínio Crítico de Alunos de Contabilidade. Revista de Educação e Pesquisa em Contabilidade - REPEC, v.1, n.2, art.3, p.43-70. Mai/Ago, 2007.

ENNIS, ROBERT H. Critical Thinking Assessment. Theory and Practice, Volume 32, Number 3, Summer 1993, College of Education, The Ohio State University.

Manual supplement for The Ennis-Weir Critical Thinking Essay Test, 1998.

ENNIS, ROBERT H.; WEIR, Eric. The Ennis-Weir Critical Thinking Essay Test. Pacific Grove, CA: Midwest Publications, 1985.

ENNIS, ROBERT H.; MILLMAN, J.; TOMKO, T. N. Cornell critical thinking tests level X \& level Z: Manual. Pacific Grove, CA: Midwest Publications, 1985.

FACIONE, Peter A. Critical Thinking: A Statement of Expert Consensus for Purposes of Educational Assessment and Instruction "The Delphi Report". Santa Clara University. California Academic Press, Millbrae, CA, 1990. ERIC Doc. Nº: ED 315423

FIELD, Andy. Descobrindo a estatística usando o SPSS. Trad. Lorí Viali. 2. ed., Porto Alegre: Artmed, 2009.

KIMEL, Paul. A Framework for Incorporating Critical Thinking into Accounting Education. Journal of Accounting Education, Vol. 13, №3, pp. 299-318, 1995.

LIPMAN, Matthew. Critical Thinking: what can it be? Analytic Teaching. [S.1.], v. 8, p. 5-12, 1988.

MCMILLAN, James H. Enhancing college students' critical thinking: A review of studies. Research in Higher Education. [S.1.], v. 26, p. 3-29, 1987.

MCPECK, John. Critical Thinking and Education. New York: St. Martin's Press, 1981.

PASSOS, Ivan Carlin. Raciocínio crítico de alunos de graduação em Ciências Contábeis: aplicação do modelo instrucional de Richard Paul. Faculdade de Economia, Administração e Contabilidade da Universidade de São Paulo. São Paulo, 2011. 250 p. (Tese de Doutorado)

PASSOS, Ivan Carlin ; CORNACCHIONE JR., E. B. ; GAIO, Luiz Eduardo ; MORI, J. S. ; BRITO, E. ; PEREIRA, Fernando da Silva . Raciocínio crítico dos alunos de graduação em Ciências Contábeis da FEA-USP: Uma aplicação do modelo instrucional de Richard Paul. In: XXXVII EnANPAD 2013, Rio de Janeiro, 2013.

PAUL, Richard W. Critical Thinking: How to prepare Students for a Rapidly Changing World. Santa Rosa, CA, USA. Foundation for Critical Thinking, 1995.

PAUL, Richard W.; ELDER, Linda. Critical Thinking: Basic Theory and Instructional Structures Handbook. Santa Rosa, CA, USA. Foundation for Critical Thinking, 2000.

PITHERS, R.T.; SODEN, Rebecca. Critical Thinking in education: a review. Educational Research, Vol. 42, n³, pp. 237- 249, 2000.

QUITADAMO, Ian J.; FAIOLA, Celia L.; JOHNSON, James E.; KURTZ, Martha J. Community-Based Inquiry Improves Critical Thinking in General Education Biology. Vol. 7, 327-337, CBE - Life Sciences Education, Fall 2008 .

REED, Jennifer H. Effect of a Model for Critical Thinking on Student Achievement in Primary Source Document Analysis and Interpretation, Argumentative Reasoning, Critical Thinking Dispositions, and History Content in a Community College History Course. Tese de Doutorado em Filosofia. Universidade do Sul da Florida. Faculdade de Educação. Florida, EUA, 1998. 
RIESENMY, M.R. et al. Retention and transfer of children's self-directed critical thinking skills. Journal of Educational Research. [S.1.], v. 85, p. 14-25, 1991.

SIEGEL, Harvey. Educating Reason: Rationality, Critical Thinking and Education. New York: Routledge, 1988.

SORMUNEN, C.; CHALUPA, M. Critical thinking skills research: Developing evaluation techniques. Journal of Education for Business. [S.1.], v. 69, p. 172-177, 1994.

STONE, D. N.; SHELlEY, M. K. Education for accounting expertise: A field study. Journal of Accounting Research. [S.1.], v. 35, p. 35-61, 1997.

WILlinghaM, Daniel T. Critical Thinking: Why is it so hard to teach?. American Federation of Teachers. American Educator, v.31, n.2, Summer, 2007.

WILSON, Richard M. S. Accounting education research: a retrospective over ten years with some pointers to the future. Accounting Education: An International Journal. [S.1.], v. 11, issue 4, p. 295-310, 2002. 